\title{
Guyana: el macrodesarrollo de las fuerzas de seguridad
}

Humberto García Muñiz

\section{“...una intervención abierta; la intervención encubierta fue la de Es- tados Unidos."}

En las primeras elecciones bajo el sufragio electoral en Guyana, celebradas en abril de 1953, resultó triunfante por una mayoría abrumadora el partido nacionalista-marxista, Partido Progresista del Pueblo. cuyo líder era Cheddi Jagan, de descendencia indoriental, dentista de 30 años, graduado en Estados Unidos.' El Partido Progresista del Pueblo abogaba por "una Guayana libre e independiente", para asi construir "una sociedad justa y socialista. en la cual todas las industrias del país serán poseídas social y democráticamente para el bien común". Luego de 133 días de su triunfo electoral, el Partido Progresista del Pueblo se convirtió en la primera víctima de la guerra fría en el hemisferio occidental. al desembarcar tropas británicas el 9 de octubre y ser decretada la suspensión de la constitución (en ese orden):

El Gobierno de Su Majestad, ha decidido que la Constitución de Guayana Británica sea suspendida para prevenir la subversión comunista del Gobierno y una crisis que ponga en peligro el orden público y económico... La facción en el poder ha demostrado por sus actos y discursos que están preparados a llegar a cualquier extremo, incluyendo la violencia, para convertir la Guayana Británica en un estado comunista. ${ }^{3}$

Los intereses británicos más importantes en Guyana estaban en el azúcar. Tres compañias controlaban 20 plantaciones y contaban con activos de más de 20 millones de libras. La más importante era la Booker Brothers, McConnell \& Co., que poseía 12 plantaciones y 11 factorias centrales. Además tenia destilerías, aserraderos, muelles, tiendas al por mayor y al detalle, ranchos ganaderos, y otros negocios. Por la magnitud y diversificación de las inversiones de esta compañia en el pais, se le conocía popularmente como "Booker's Guiana". Fue precisamente contra la Booker que el sindicato controlado por el Partido Progresista del Pueblo, el Sindicato Industrial de Guyana, declaró una huelga para que se le reconociera como representante de los obreros de la caña. Durante esta huelga, que se extendió del 30 de agosto al 24 de septiembre, el gobernador colonial utilizó a la policía para intimidar a los huelguistas. ${ }^{4}$ La realidad social, hasta el dia del desembarco de las

\footnotetext{
' En los Estados Unidos Jagan contrajo matrimonio con una enfermera de tendencias socialistas. Janet Rosenberg. Vease: Cheddi Jagan, The West on Trial, The Figh for Guarama's Frecdom. Nueva York. International Publishers. 1972, p. 55. George Padmore. "A Review of Constitutional Development in Guyana", en Linired Isia. 6. núm. 5. noviembre. 1954. p. 239-240.

3 Cheddi Jagan, op. cil., p. 125.

+ Vèase: George Padmore, op. cit., p. 240-241.
} 
tropas británicas, a más de dos semanas del cese de toda actividad huelguista. la colonia se encontraba en paz y sin ningún disturbio.

La iniciativa británica fue apoyada por los Estados Unidos, que a su vez tenían intereses económicos y estratégicos en juego. Los intereses económicos los constituian las inversiones en la bauxita, la Demerara Bauxite Company (DEMBA) y la Berbice Company Ltd. Los intereses estratégicos y de seguridad estaban conformados por la vulnerabilidad de los yacimientos petroleros de la Standard Oil en Venezuela, la de las refinerias en las Antillas Holandesas, y la del Canal de Panamá. George Padmore señala que, de acuerdo con fuentes diplomáticas en Londres, los Estados Unidos amenazaron con reocupar las dos bases que obtuvo en 1941 en arrendamiento por 99 años, si Gran Bretaña no desembarcaba tropas navales y militares. El cónsul general de los Estados Unidos en las Indias Occidentales arribó a Guyana el mismo día del desembarco de tropas y sostuvo consultas con el gobernador colonial y los comandantes navales y militares.

El desembarco ha sido descrito como "una intervención abierta; la intervención encubierta fue la de los Estados Unidos". "Ambos paises continuaron su intervención hasta que lograron la división del Partido Progresista del Pueblo. El principal líder afroguyanés, Forbes Burnham, fundó en 1957 el Congreso Nacional del Pueblo. De esta forma, la política divisionista de la metrópoli se nutrió de la realidad social de la colonia:

La sociedad... estaba dividida verticalmente más a lo largo de líneas raciales-culturales, que lo que estaba dividida en líneas de clase; o sea, para ser más preciso. estando de hecho dividida en dos sectores, las masas se volvieron a la identidad cultural racial, cuando se vieron forzadas a buscar algún tipo de refugio de la división reciproca y del desprecio de sí mismo a fines de $1964 .^{\text {? }}$

\section{Desestabilización en la década de los sesenta}

La intervención de los Estados Unidos durante las décadas de cincuenta y de sesenta fue predominantemente en el movimiento laboral. ${ }^{8}$ A pesar de esta campaña, Jagan resultó victorioso en las

\footnotetext{
Véase: George Padmore, ibid., p. 243-244.

"Anthony P. Maingot. "The Difficult Path to Socialism in the English-Speaking Caribbean", en Richard W. Fagen, editor. Capitalism and the State in United Stales-Latin American Relations. Stanford. Calif.. Stanford University Press, 1979. p. 264.

Gordon K. Lewis. The Growth of the Modern W'est Indies. Nueva York, Monthly Review Press. 1968, p. 276-277. Para un excelente estudio, del complejo cuadro etnosocial de Guyana véase: Andrés Serbin. Nacionalismo, etnicidad y politica en la Repiblica Conperativa de Guyana. Caracas. Editorial Bruguera Venezolana. 1981.

"Véase: Michael J. Sussman. AlFLD: U.S. Troian Horse in Latin America and the Caribhean. Washington. D. C.. EPICA, 1983. El senador Ellender, refiriéndose a la pequena ayuda que Estados Unidos daba a Guyana, comentaba en 1958: "No veo ninguna razón para que Estados Unidos derrame buen dinero en este país, bajo el pretexto de un programa de ayuda, para beneficiar a un manojo de terratenientes ricos... A mi juicio toda ayuda debe ser descontinuada enseguida. La Guayana Británica es uná colonia británica. No se le debe extender ayuda de Estados Unidos a ese país. Si la ayuda se necesita, eso es un asunto para los británicos."
} 
elecciones de 1957 y 1961 . La violencia que azotô a Guyana de 1962 a 1964 tenía como fin desestabilizar el gobierno del Partido Progresista del Pueblo, pues no se permitiria que Guyana alcanzara su independencia bajo Jagan. La independencia se lograría en 1966 con Burnham en el poder. El binomio británicoestadunidense logró las metas deseadas, como bien lo resumió Arthur M. Schlesinger, un partícipe del drama:

La visita de Burnham (a los Estados Unidos) dejó la sensación, como yo le informara al Presidente, que una Guayana Británica bajo Burnham (si Burnham se compromete a una politica multirracial) nos causaria muchos menos problemas que una Guayana Británica bajo Jagan. Y el camino estaba abierto para llevar esto a cabo, porque la fuerza parlamentaria de Jagan era mayor que su fuerza popular; ganó $57 \%$ de los asientos sobre una base de $42.7 \%$ de los votos. Una solución obvia seria establecer un sistema de representación proporcional. Después de una prolongada discusión, el Gobierno británico lo hizo al fin en octubre de 1963 y las elecciones celebradas finalmente a fines de 1964 produjeron un gobierno de coalición bajo Burnham. Con mucha tristeza y turbulencia, la Guayana Britanica parece estar fuera del bloque comunista con toda seguridad. ${ }^{9}$

Durante el periodo de 1962 a 1964 todavia se encontraban en el pais las tropas británicas desembarcadas en 1953, y no fue sino hasta última hora, mejor dicho, hasta ya pasada la hora, que fueron llamadas para ayudar a la policía en la pacificación del país. Esta situación arroja un claro contraste con el año 1953 cuando se desembarcaron tropas en una colonia en paz y con Jamaica en 1959, donde se respondió de inmediato a la solicitud de tropas de Norman W. Manley. En Guyana la situación llegó al colmo cuando el jefe de la policía rehusó movilizar en un momento crucial a los hombres bajo su mando, aun cuando las órdenes venian de la ministra de Asuntos Internos, Janet Jagan, a la cual estaba supeditado.

Para dar una idea de la magnitud de la violencia política y racial que se desató. mencionaremos que solamente en el año 1964 2500 familias (más de 15000 personas, indorientales en su mayoria) tuvieron que abandonar sus hogares y asentarse en comunidades de su propio grupo racial. Hubo 176 muertos, 935 heridos y 1435 casas quemadas. El Sunday Times estimó que el costo fue bajo para la CIA: alrededor de 250000 dólares. $^{10}$

Allen J. Ellender. A Review of United States Government Operations in Latin Amorica. Washington. D. C.. U. S. Government Printing Office, 1959, p. 441.

"Arthur M. Schlesinger, A Thousand Days. Nueva York. Houghton. 1965. p. 713. Drew Pearson escribió en su columna del 22 de marzo de 1964: "No estaba en el comunicado emitido por los Estados Unidos e Inglaterra después de la reunión Kennedy-Macmillan, pero lo más importante que acordaron fue que los británicos rehusaran darle la independencia a Guayana por causa de la huelga general contra el primer ministro procomunista. Cheddi Jagan. La huelga fue inspirada secretamente por una combinación de dineros de la Agencia Central de Inteligencia de los Estados Unidos y el servicio de inteligencia británico. Esta le dio a Londres la excusa que queria. Guayana Británica no ha recibido la independencia. y otro gobierno comunista en lo que fue una vez un lago estadunidense ha sido detenido temporalmente." Citado en: Cheddi Jagan, op. cit. p. 248-249.

"Vease: Anónimo. "Guyana: The Face Behind the Masks". en Covert Action IIformation Bulletin. nüm. 10, agosto/septiembre, 1980, p. 19. Para información 
La policia, casi a lo largo de toda la historia de Guyana, ha fungido de fuerza militar, por ser el único cuerpo armado para mantener el orden interno y la defensa externa. El gobierno del Partido Progresista del Pueblo fracasó en obtener la lealtad y el apoyo de la policia. Más tarde este partido ha alegado que la policía. por estar integrada en su mayoría por negros, respaldó al Congreso Nacional del Pueblo. Además de la cuestión racial era de esperarse que la policía le diera el respaldo al Congreso Nacional del Pueblo, ya que la metrópoli también se lo brindaba, y la policía. "como brazo intimo del estado colonial le dio su lealtad, antes que a nadie, a los oficiales coloniales..."

\section{De Unidad de Servicio Especial a Ejército}

En su infructuosa pugna con la administración colonial, lo más que Jagan pudo conseguir fue la creación de una Unidad de Servicio Especial, que estaba bajo el gobernador colonial y su control operacional en manos del jefe de la policía. Jagan protestó en vano esta extraña linea de autoridad, argumentando que la ministra de Asuntos Internos tenía en su jurisdicción el orden interno y la seguridad pública.

La Unidad de Servicio Especial, establecida en 1964, tenía deberes tan ambiguos como para ejercer funciones policiacas y militares (preservar la ley y el orden, prevenir y detectar el crimen, la defensa de la colonia) excepto por una (la protección de la propiedad privada), que reflejaba el temor ideológico oficial al Partido Progresita del Pueblo. La Unidad de Servicio Especial podia ser movilizada junto con la policía y las tropas británicas. Varios cadetes de la Unidad fueron enviados a Gran Bretaña para un adiestramiento militar de dos semanas. Todos los gastos de la Unidad fueron sufragados por el gobierno británico. El reclutamiento de la Unidad fue balanceado racialmente y la fuerza de 500 miembros era muy disciplinada y estaba bien equipada.

La Unidad no vio acción porque ese mismo año se formó un gobierno de coalición del Congreso Nacional del Pueblo y la Fuerza Unida, un pequeño partido de derecha por lo cual amainó considerablemente la violencia. La Unidad se convirtió en noviembre de 1965 en el ejército de Guyana y entonces las tropas británicas abandonaron el país. ${ }^{12}$ Fue así como Guyana se convir-

más detallada véase: Colin V. F. Henfrey. "Foreign Influence in Guyana: The Struggle for Independence". en Emannuel de Kadt. editor, Patterns of Foreign In/li'ince in the Caribbean. Londres. Oxford University Press, 1972, p. 49-81, y "CIA Intervention in Guyana: A Documentation". Thunder. 8. núm. 1. Guyana. enero/ marzo. 1976. p. 27-37. Esta es la revista oficial del Partido Progresista del Pueblo.

$"$ George K. Danns. Domination and Power in Gulana. A Study of the Police in a Third Horld Context. New Brunswick. Transaction Books. 1982, p. 34.

1: La transformación de la Unidad de Servicio Especial a ejército fue aceptada por el Partido Progresista del Pueblo. Este partido introdujo unas enmiendas para que la oposición tuviera representación en la Junta de Defensa y la de Nombramientos. El Congreso Nacional del Pueblo las rechazó. Véase: Malcolm R. M. McFarlane. "The Military in the Commonwealth Caribbean: A Study of Comparative Institutionalization". tesis doctoral. The University of Western Ontario. 1974. p. 158-159. David de Caires comentaba a principios de 1965: "En un pais como éste. donde hay divisiones políticas profundas y sin una tradición de subordinación militar que lleve mucho tiempo. la seguridad. es, por supuesto. un pro- 
tió en el único territorio británico en el Caribe (junto con Antigua) que estableció un ejército antes de obtener su independencia.

El ejército de Guyana se constituyó de oficiales británicos en calidad de préstamo y cadetes guyaneses que habían sido enviados a estudiar a las academias militares de Mons y Sandhurst en Gran Bretaña. Como era natural, se estructuró a imagen y semejanza de un regimiento británico.

\section{Los Estados Unidos y Guyana: la política de contrainsurgencia y la policia}

No hemos encontrado evidencia de relación alguna del ejército guyanés con los programas de ayuda militar de Estados Unidos, por lo menos hasta la década de los ochenta. En la segunda mitad de la década de los sesenta, soldados guyaneses se adiestraron en una academia militar de Brasil, especializada en combate en la jungla. Este contacto se estableció luego del apoyo de Brasil a la posición de Guyana ante el reclamo territorial de Venezuela.

No obstante. Estados Unidos sí brindô ayuda a la policía de dos maneras: adiestramiento y donación de equipo. De 1966 a 1970 unos 921 oficiales de la policía recibieron adiestramiento en las propiedades de la Oficina de Seguridad Pública en América Latina, y a fines de 1973, se impartió a otros 53 en Estados Unidos. Varios oficiales fueron adiestrados en la escuela de la CIA en Washington. D. C. Entre éstos se encontraban dos altos funcionarios de las fuerzas de seguridad, Cecil "Skip" Roberts, jefe de la policia hasta mayo de 1985. y el brigadier Norman McLean, actual comandante en jefe del ejército. ${ }^{\prime \prime} \mathrm{El}$ gasto total bajo el Programa para la Seguridad Pública fue de 1299000.00 dólares.

La Agencia Internacional para el Desarrollo donó equipo de contrainsurgencia durante este periodo, que incluía equipo de comunicaciones, jeeps, camiones, carros patrullas, embarcaciones y motores. ${ }^{14}$ McFarlane destaca que esta ayuda puede considerarse como insignificante, pero en realidad "es de un valor inapreciable para el desarrollo y la movilidad de una fuerza policiaca severamente limitada por la falta de vehículos y equipo anciliario". 15

\section{Los Estados Unidos y Guyana: el acuerdo de 1966}

Resultó de capital importancia el acuerdo de 1966, por el cual los Estados Unidos obtuvieron el derecho a construir bases militares temporales para desembarcar equipo y personal militar en

blema... No tenemos ejército local en este país. En resumen, ése es el problema. Lo que el gobierno debe hacer es preparar un documento sobre el problema de seguridad exponiendo sus planes para el futuro. especialmente si consideramos su demanda de una independencia temprana." David de Caires. "The Security Problem". New Ilorld. 1, num. 7. Guyana. 2 de febrero de 1965. p. 10.

13 A mediados de 1985 se nombró a Bahram Raghubir como jefe de la policia. Vease: Caribbean Insight, julio, 1985. p. 7.

${ }^{4}$ Michael T. Klare. Cynthia Arnson. et al. Supplying Repression. U. S. Support

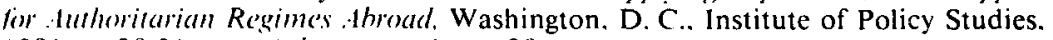
1981. p. 20-21, y Anónimo, (p). cil., p. 20.

is Malcolm R. M. McFarlane. opl. cit.. p. 201. 
Atkinson Field y Makoura, y a sobrevolar el territorio de Guyana. ${ }^{16}$ Este acuerdo, que tenía una duración de 17 años, abrogó todos los tratados firmados por Gran Bretaña, inclusive el de 1941. referente a Atkinson Field y Makoura. Asimismo, fue el cumplimiento de un compromiso del Congreso Nacional del Pueblo, tal como decía su programa para las elecciones de 1965:

Al convertirse en gobierno el Congreso Nacional del Pueblo renegociará el acuerdo de la base Atkinson y recobrará nuestro territorio del gobierno de Estados Unidos de América, con el propósito de desarrollarlo en el interés nacional de Guyana a su plena capacidad. ${ }^{17}$

De las dos bases que los Estados Unidos obtuvieron en Guyana, la aérea. Atkinson, fue la que tuvo alguna importancia y sólo durante la campana de Africa del Norte, como pista de aterrizaje de tránsito. Durante la discusión sobre la cuestión de Atkinson Field, sólo se mencionó su valor político, porque carecía del estratégico. Una observación en torno a las bases fue muy interesante. Decía Louis Bone que la existencia de una base más grande y activa no evitó que Cuba saliera de la esfera de influencia estadunidense, mientras que la ausencia de una no fue óbice para el desembarco de miles de marinos de los Estados Unidos en la República Dominicana para defender sus alegados intereses. ${ }^{18}$

\section{Un "Ejército del Pueblo" y las elecciones}

Un año después de las elecciones de 1968, las que el Congreso Nacional del Pueblo amañó para formar una mayoría parlamentaria sin la Fuerza Unida, se reemplazó a toda la oficialidad británica que quedaba en calidad de préstamo en el ejército. En febrero de 1970 se proclamó la "República Cooperativa de Guyana", y para octubre el primer ministro Burnham aseveró que el ejército no debería ser un cuerpo elitista, sino un "ejército del pueblo":

Yo no comparto con los británicos el concepto de que el Ejército esté separado. sea distinto... y sea leal al gobierno en turno. Yo, como Primer Ministro. espero que ustedes sean leales a este Gobierno. Si hay algún otro gobierno, es asunto de ustedes decidir sobre eso, pero, en lo que a mi concierne, no quiero ninguna lealtad abstracta. Tiene que ser una lealtad franca, de arriba para abajo, y tiene que estar fundamentada en una apreciación de la filosofía de este gobierno. En el GDF no pueden estar aquellos que creen que la forma de vida y organización económica capitalista es buena para Guyana. ${ }^{19}$

" Véase: "Article by Cheddi Jagan. Leader of the Opposition in Guyana: Excerpt from 'A Review of Guyana's Foreign Policy' International Affairs Quarterly'. vol. 4. 67". en Roy M. Preiswerk, editor, Documents on International Relations in the Caribbean. Rio Piedras. Instituto de Estudios del Caribe, Universidad de Puerto Rico y San Agustín. Instituto de Relaciones Internacionales. Universidad de las Indias Occidentales. 1970. p. 62-65.

" "New Airport". New World. 1, núm. 11. abril. 1965, p. 9.

1" Véase: Louis Bone. "Atkinson Deal, Pt. I", New Horld, 1, núm. 15, 28 de mayo. 1965. p. 13-17. y "Atkinson Deal". Ne» U'orld, 1. núm. 16. 11 de junio. 1965. p. 13-16.

${ }^{19}$ El texto integro del discurso se reproduce en: Malcolm R. M. McFarlane. op. (iil. p. $365-373$. 
Pocos meses después de su discurso, Burnham reorganizó el ejército, transfiriendo, ascendiendo o retirando a los oficiales de formación británica, que fueron adiestrados en Gran Bretaña o provenientes del Cuerpo de Voluntarios de la Guayana Británica y nombró. en puestos claves, a oficiales más jóvenes. ${ }^{20}$ Obviamente. el levantamiento de un sector del ejército de Trinidad y Tobago en ese año también debe haber tenido su impacto en Burnham.

Las elecciones de 1973 demostraron el control que Burnham tenía sobre el ejército. Al finalizar la votación, el ejército se llevó las urnas a sus cuarteles generales en Thomas Lands y a nadie le fue permitido acompañarlas. ${ }^{21}$ Burnham obtuvo la mayoría parlamentaria de las dos terceras partes que necesitaba para implantar la "doctrina de supremacia" de su partido sobre todo el aparato estatal, que incluia, por supuesto, a las fuerzas de seguridad.

Un aspecto importante de la política de Burnham hacia el ejército fue el rompimiento del balance racial que originalmente tenía el cuerpo cuando era la Unidad de Servicio Especial. A principios de la década de los setenta McFarlane apuntaba que habia muy pocos indorientales reclutados en el ejército y "que desde 1970 esta situación parece ser una política deliberada para seguir alimentando la tendencia heredada a favor de los afroguyaneses en las fuerzas de seguridad".?2

\section{Gastos militares}

En los cuadros 1 y 2 observamos que en 1967 los gastos militares y sus proporciones en comparación con los GGC y el gasto per cápita eran muy altos, lo que era de esperarse ya que Guyana adviene a su independencia escindida racial y políticamente. La relación GM/per cápita que era de 13 dólares en 1967. desciende y es en 1972 cuando empieza a subir otra vez, hasta llegar a los 13 en 1975. En el cuadro 3 vemos que esta proporción aumenta sustancialmente en 1975, 1976 y 1977, para luego bajar y estabilizarse.

La proporción GM/GGC comenzó alta en 1967 , con $7.2 \%$, pero se redujo y en 1976 llegó a $2.6 \%$. En el cuadro 3 notamos que el aumento significativo en esta relación ocurre en 1975,1976 y 1977, seguido por una baja notable hasta que se estabiliza en $6 \%$. Los aǹos 1974, 1975 y 1976 fueron de frecuente actividad huelguista en la industria cañera. Una de las causas era la otrora petición del Sindicato Industrial de Guyana, ahora conocido como el Sindicato Agricola de Guyana, reconocida por la Asociación de Productores de Azúcar como la unidad negociadora. En diciembre de 1976. el Sindicato Agrícola de Guyana obtuvo una enorme mayoria en una elección. El impacto de las huelgas para noviembre de ese año fue tal, que se perdieron 1645000 dias-hombre. Du-

21) El Cuerpo de Voluntarios fue establecido en 1948, a petición del gobernador colonial. con el propósito de defender el país en tiempo de guerra y de ayudar al poder civil. El cuerpo fue movilizado durante el periodo de suspensión de la constitución en 1953 y durante el periodo de desórdenes de 1962 a 1964 . Véase: Malcolm R. M. McFarlane. op. cit.. p. 55-56.

II Vease: Michael Harris. "Different Folks, Same Old Strokes, Burnham Hijacks the Ballot Box". Tapia. 4. núm. 8. Trinidad y Tobago. febrero, 1974, p. 10.

Malcolm R. M. McFarlane. op. cit., p. 174. 


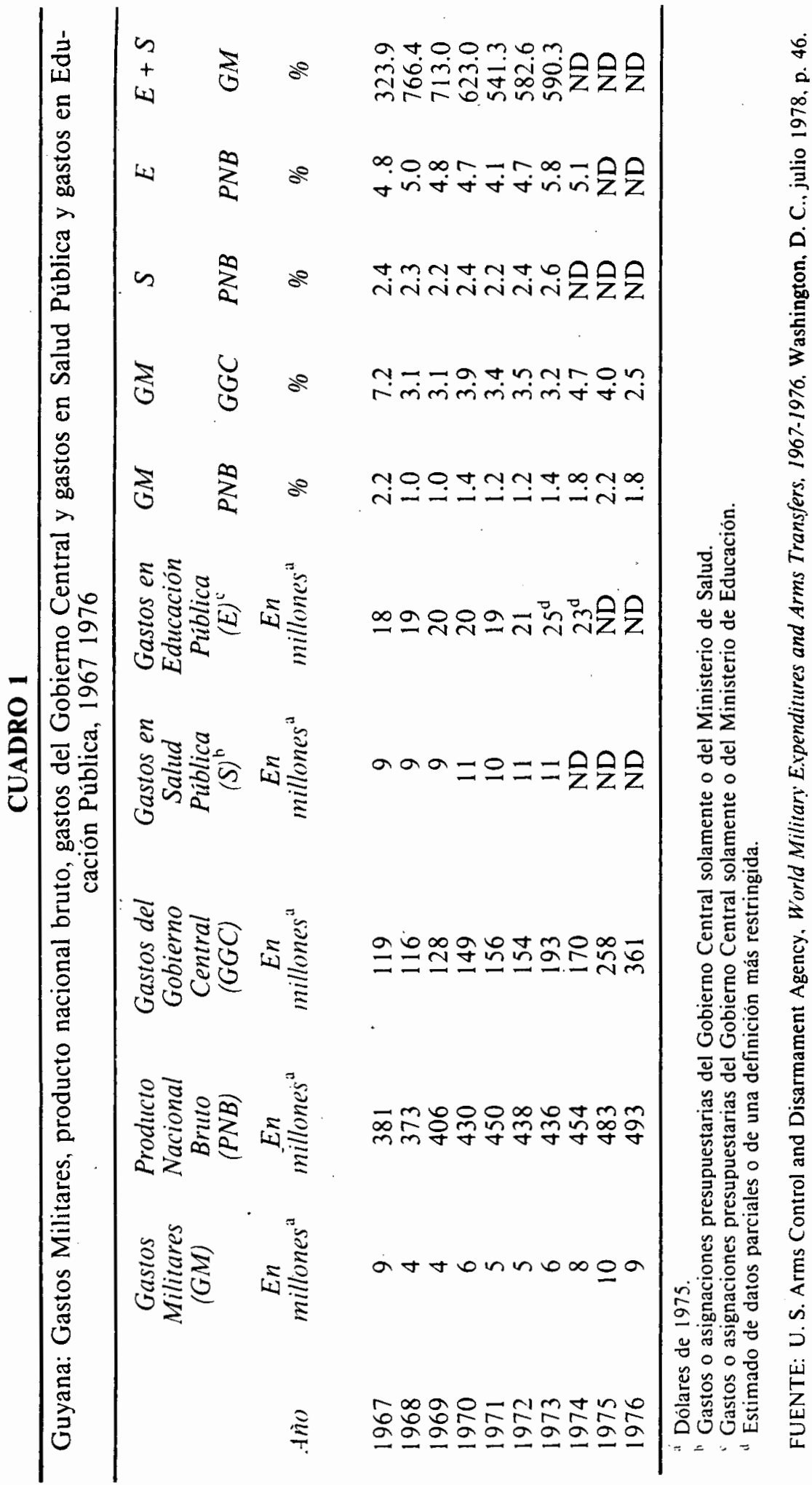




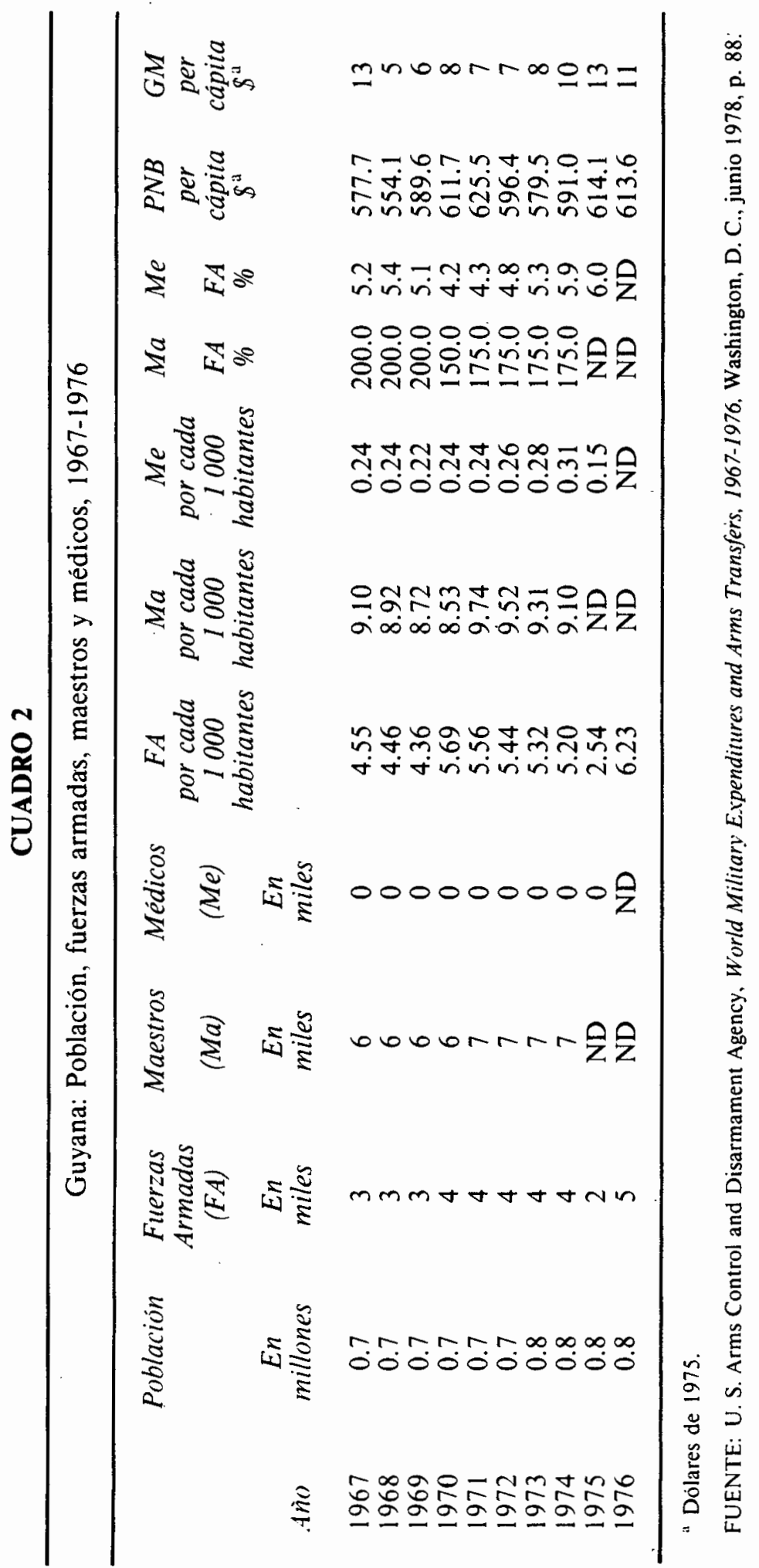


rante las huelgas, miembros del ejército y de la policía, con protección armada. cortaron la caña, lo que sin duda debió haber inflado los gastos de estas fuerzas. ${ }^{23}$

El número de las fuerzas militares tuvo un aumento sustancial de 1972 a $1982 . .^{24}$ Una comparación de los indicadores directamente relacionados con el ejército en 1972 con los de 1982 arroja incrementos notables. En los gastos militares vemos un aumento de $266 \%$, en GM/GGC de $85 \%$, y de FA por cada 1000 de $54 \%$.

La gravedad de la crisis económica se observa en el cuadro 3, donde se muestra que el PNB estaba en 492 millones de dólares, en 1975 sube a $\$ 596$ millones y en 1982 cae estrepitosamente a $\$ 493$ millones. Más dramático aún es el descenso del PNB per cápita, que en 1972 era de $\$ 706$ y en 1982 de $\$ 616$. Recordemos que el precio del azúcar se cuadruplicó entre 1973 y 1975 . En el mismo periodo, el del arroz se duplicó y hubo aumentos en la bauxita aluminada y calcinada. A partir de 19.76 la economia de Guyana entró en una crisis de producción que dura hasta hoy dia.

Los años 1971 a 1976 fueron fundamentales para la transformación de Guyana a un capitalismo de estado. En 1971 Guyana nacionaliza DEMBA. la principal empresa generadora de divisas e ingresos fiscales. ${ }^{26}$ En los años 1974, 1975 y 1976 se acelera el proceso de nacionalización con indemnización de firmas (en su mayoría británicas), como la Guyana Timbers (madera), Reynolds (bauxita), Bookers (azúcar, tiendas y otras empresas), Jewels (azúcar), Berger Paints (pintura), Sprostons (ingeniería y aserradero) y otras. En suma, para mediados de la década de los setenta, los sectores más productivos (azúcar y bauxita), el comercio de exportación e importación, gran parte de las comunicaciones y el transporte público, entre otros, estaban en manos del Estado, por lo que el gobierno reclamaba que poseia un $80 \%$ de la economia.

En este periodo se estrechan los lazos con Cuba y el Movimiento de los No Alineados. ${ }^{27}$ También se establecen lazos de co-

"3 Véase: Carihbean Monthly, Bulletin. 9, núm. 1-12, noviembre/diciembre, 1975. p. 15, y Caribbean Monihly. Bulletin, 10, núm. 1, enero, 1976, p. 20.

it En 1975 la edad de ingreso al ejército se redujo de 18 a 16 años, y se permitió el ingreso con 14 aǹos con consentimiento de los padres. Véase: Caribbean Monthly Bulletin. 9. núm. 10, octubre. 1975, p. 15.

- Para una excelente discusión de la situación guyanesa, con énfasis en el marco económico. véase: Clive Y. Thomas. "State Capitalism in Guyana: An Assessment of Burnham's Co-operative Socialist Republic", en Fitzroy Ambursley y Robin Cohen. editores. Crisis in the Caribbean. Nueva York. Monthly Review Press. 1983. p. 27-48. y del mismo autor. "Guyana: The Rise and Fall of Co-operative Socialism". en Anthony Payne y Paul Sutton, editores, Dependency under Challenge'. The Political Economy of the Commonuealth Caribbean. Gran Bretana, Manchester University Press. 1984, p. 77-104.

: Véase: Norman Girvan. "El Conflicto de Guyana-Alcan y la nacionalización de DEMBA". Estudios Internacionales. V. núm. 19. julio/septiembre de 1972. p. $71-90$

Véase: Henry Gill. "Guyana’s Decision to Recognize Cuba". Ponencia presentada en la Conferencia sobre Tendencias y Problemas Contemporáneos en las Relaciones Internacionales del Caribe. Puerto España. Trinidad y Tobago, 23-27 de mayo de 1977. Gill hace un recuento de las relaciones del gobierno de Jagan con Cuba. Guyana acordó en $1961^{\circ}$ venderle excedentes de su producción de arroz por 5 aǹos a precios más altos que los del mercado mundial. Durante la crisis de 1963 en Guyana. Cuba pagó por adelantado un cargamento de traviesas y envió alimen- 


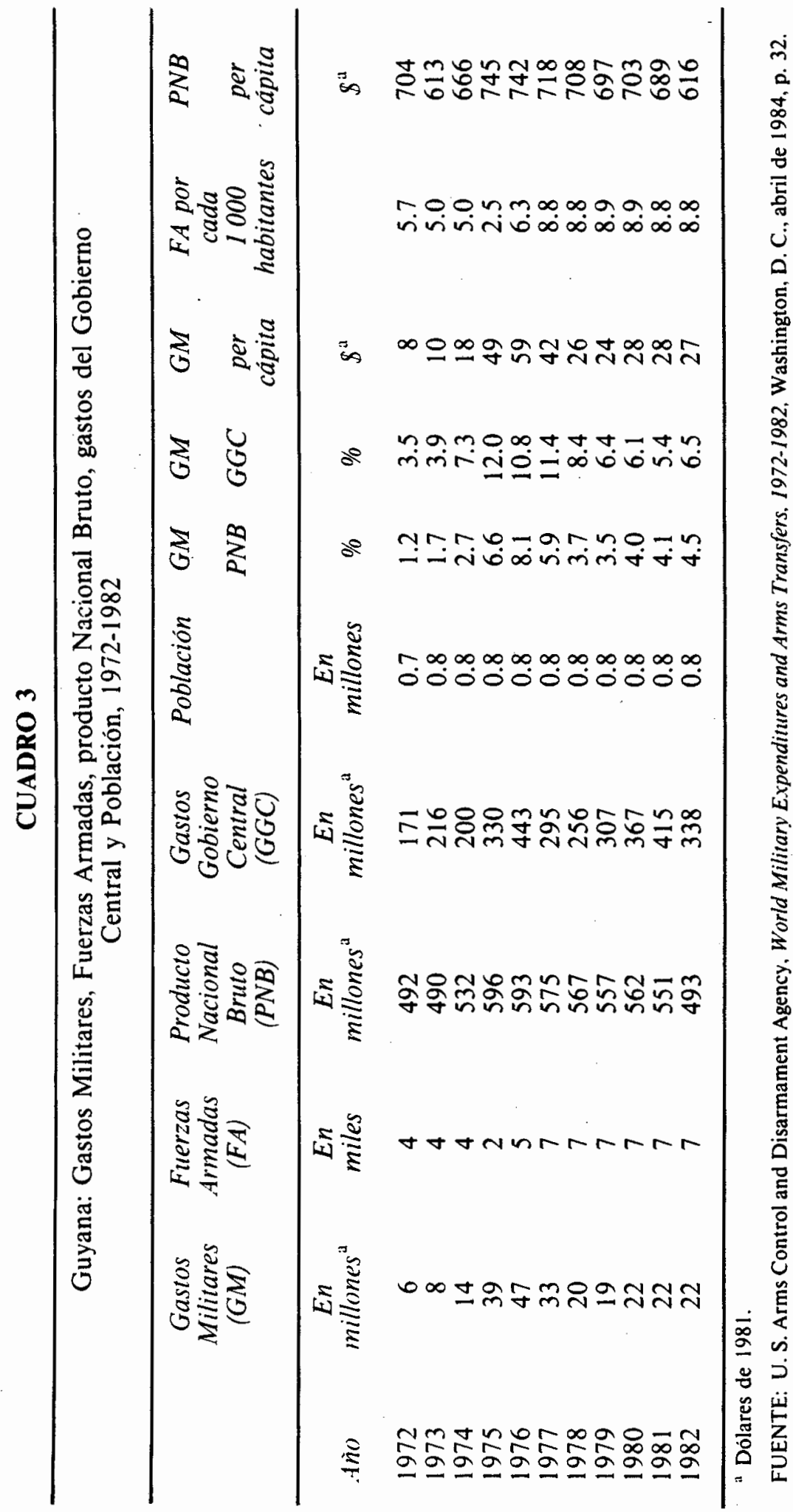


laboración con Hungria, Rumania y Checoslovaquia, relacionados con la industria de la bauxita, y se solicita el ingreso al Consejo de Ayuda Mutua Económica. ${ }^{28}$ Dentro de este contexto altos funcionarios del gobierno mencionaron varias veces que el país estaba en peligro de invasión y que había problemas en las fronteras de Brasil, Venezuela y Surinam. ${ }^{29}$ En 1977 Guyana anunció que Estados Unidos accedió a la anulación del acuerdo de 1966, que daba a este último ciertos derechos sobre Atkinson Field, hoy el aeropuerto de Timehri. ${ }^{30}$

El Partido Progresista del Pueblo, reconociendo la posición antimperialista del gobierno, ofreció "apoyo critico" al Congreso Nacional del Pueblo. En mayo de 1976 Burnham y Jagan aparecieron en la misma tribuna, y el Partido Progresista del Pueblo declaró que estaba unido al partido gobernante en la defensa de la integridad y soberanía de Guyana. ${ }^{3}$

Esta no fue la primera vez que el Partido Progresista del Pueblo asumía una posición de apoyo al Congreso Nacional del Pueblo. A raíz de la nacionalización de DEMBA, en marzo de 1971, se llegó al acuerdo conocido como el plan de paz Burnham-Jagan, que más tarde violara Burnham, en especial durante las fraudulentas elecciones de 1973. El mismo final tendria la postura de apoyo crítico del partido de Jagan ya que el Congreso Nacional del Pueblo poco tiempo después la relegó.

\section{El Servicio Nacional y la Milicia Popular}

En la década de los setenta el gobierno del Congreso Nacional del Pueblo creó dos organizaciones nuevas, tal como aparecen en el cuadro 4, con sus asignaciones presupuestarias de 1973 a 1984. El Servicio Nacional de Guyana fue establecido en 1973 para colaborar en el desarrollo económico del país, sobre todo en el interior. Su dirección ha estado a cargo de oficiales del ejército, lo que, en parte, ha impedido que cumpla sus objetivos primarios, ya que lo que se ha forjado es un cuerpo con adiestramiento y disciplina militar. El primer director general del Servicio Nacional fue Norman McLean y hoy lo dirige Joe Singh, uno de los pocos indorientales en el ejército. Sus miembros son obligados a participar en las actividades del Congreso Nacional del Pueblo y la no cooperación significa el no obtener becas y, por consiguiente, olvidarse de una carrera universitaria. Por esta militancia forzada pro Congreso Nacional del Pueblo los indorientales no apoyan al Servicio Nacional y casi toda la membresía es negra. El Servicio Nacional ha resultado en tal fracaso, que Danns hace esta valoración extrema:

tos de primera necesidad y petróleo. Para cuando el gobierno del Congreso Nacional del Pueblo proclama la independencia no hay intercambio comercial entre los dos paises.

2* Sobre el particular véase una entrevista con el primer ministro Forbes Burnham publicada en: Dire't from Cuba, 1 abril 1974, p. 6-8.

29 Caribbcan Monthly Bulletin. 9, núm. 10, octubre, 1975, p. 15, Caribbean Monthly Bulletin, 10, núm. 1, enero, 1976, p. 20; y Caribbean Monthly Bulletin. 10 , núm. 4, abril, 1976, p. 14.

"10 Vẻase: Caribbean Monthly Bulletin, 11, núms. 7-8, julio/agosto, 1977, p. 42.

"Caribbean Montly' Bulletin, 10, núms. 5-6-7, mayo/junio/julio, 1976, p. 34.

32 Para más información véase: Norman Girvan, op. cit., p. 88-90, y Harold 


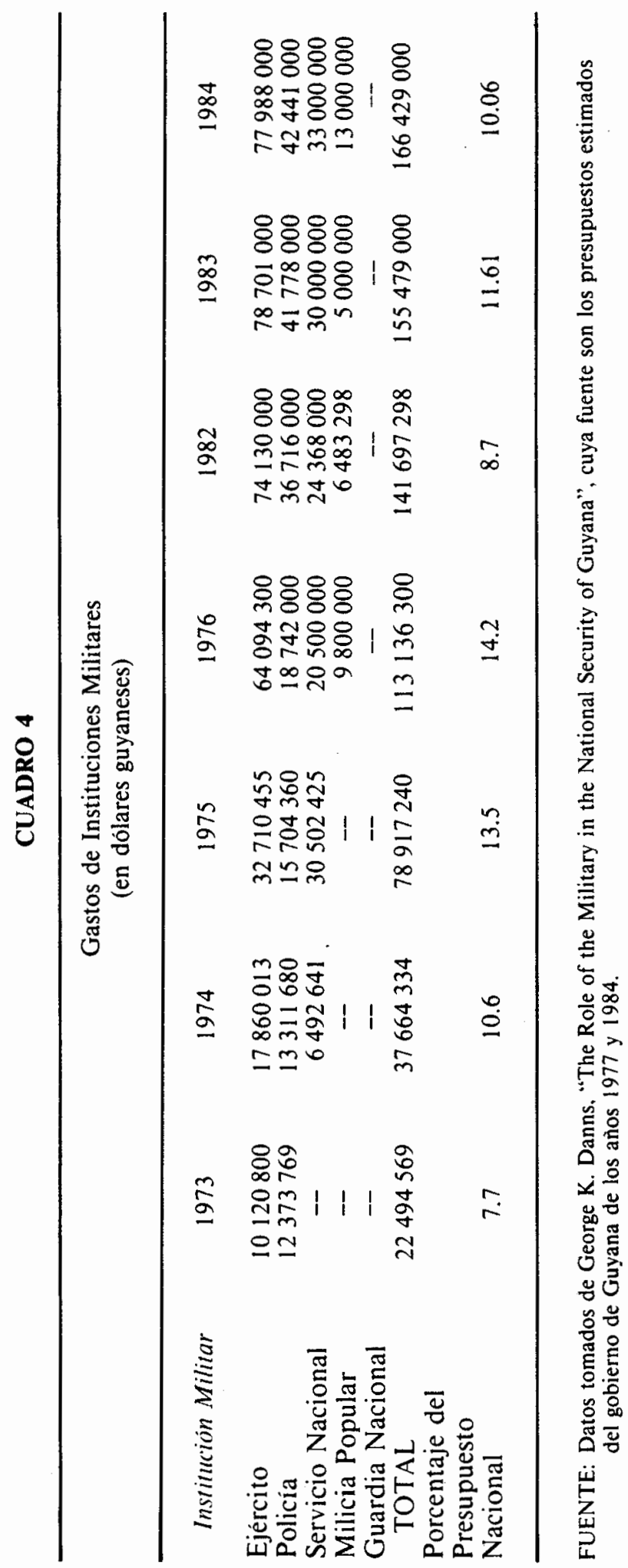


Parece que un vuelco del destino ha traído a los negros (cuyos padres... eran esclavos) de vuelta a la atmósfera de una institución total, similar a la plantación. como son los asentamientos del Servicio Nacional de Guyana. $^{33}$

La Milicia Popular de Guyana, creada en 1976, es un cuerpo paramilitar de tiempo parcial y sus directivos provienen del ejército. Sus funciones son similares a las de la policia. Se le considera el brazo auxiliar del ejército y de la policia, una especie de reserva. La creación de la Milicia Popular fue sugerencia de Jagan, en vista de los pretendidos esfuerzos imperialistas de desestabilizar Guyana. Burnham la aceptó y proclamó su institución en mayo de 1976. Irónicamente la composición étnica del cuerpo es predominantemente negra y la relación con el Congreso Nacional del Pueblo es tan estrecha que se le describe como la milicia del partido gobernante. El primer comandante de la Milicia Popular fue el coronel C. E. Martindale. ${ }^{34}$

\section{Burnham: omnipresente y omnipotente}

En este punto debemos recordar que en 1978 el gobierno pospuso las elecciones, y en cambio celebró un referéndum que le confirió el derecho de redactar una nueva constitución. Al igual que los anteriores ejercicios electorales bajo Burnham, el proceso fue fraudulento, lo que aprovechó el Congreso Nacional del Pueblo para reclamar a su favor el increíble $97.7 \%$ del total de votos emitidos del $71 \%$ del electorado participante. Las fuerzas de seguridad volvieron a intervenir: "Patrullas armadas, en uniforme de batalla, caminaban por la ciudad en fila india, como en teatro de guerra., 35

La nueva constitución, proclamada en 1980, confirmó a Burnham como presidente y máxima autoridad ejecutiva, legislativa y judicial. Los poderes del Presidente no son sólo "omnipresentes, sino omnipotentes", convirtiéndose asi Burnham en "quizás el más poderoso jefe de gobierno en el Caribe anglófono y, sin duda, el individuo más poderoso en la historia de Guayana". 36

Las elecciones se celebraron ese mismo año y esta vez el fraude lo constató una comisión internacional, encabezada por Lord Avebury. Después de señalar numerosas irregularidades, la comisión dijo que

La presencia militar en algunas áreas era intimidatoria. Las urnas fue-

Lutchman. From Colonialism to Co-operative Republic, Aspects of Political Development of Gulana. Rio Piedras. Instituto de Estudios del Caribe. Universidad de Puerto Rico, 1974, p. 253-256.

33 George K. Danns, op. cit., p. 156.

${ }^{34}$ La directriz al gobierno de formar una milicia vino del comité ejecutivo del Congreso Nacional del Pueblo. Véase: Caribbean Monthly Bulletin, 10, núm. 4, abril. 1976, p. 14: Caribbean Monthly. Bullotin, 10, núms. 5-6-7, mayo/junio/julio, 1976, p. 32-33: y Caribbean Monthly' Bulletin, 10, núm. 12, diciembre. 1976. p. 27.

35 Committee of Concerned Citizens, $A$ Report on the Referendum held in GuIana, July 10th. 1978. Barbados, Cole's Printery Ltd., s. f., p. 14. En este comité estaban los partidos de oposición más importantes, el Partido Progresista del Pueblo y la Alianza del Pueblo Trabajador. Ambos promovieron la abstención.

"G George K. Danns, op. cit., p. 180. 
ron recogidas por personal militar. que evitó, por el uso de la fuerza o la amenaza de ésta. que oficiales acreditados de la oposición acompanaran o siguieran las urnas. El personal militar rehusó a representantes acreditados de los partidos de la oposición. a veces a punta de pistola. acceso al conteo. ${ }^{37}$

\section{El macrodesarrollo de las fuerzas de seguridad}

Los cuadros 4 y 5 demuestran el predominio del ejército sobre las otras fuerzas de seguridad; tiene el mayor número de miembros y se lleva la tajada presupuestaria más grande, equivalente al $47 \%$ de la asignación para la seguridad. La pérdida de importancia de la policia es conspicua y comienza a mediados de la década de los setenta. Aun el Servicio Nacional, en 1975 y 1976 tiene un presupuesto mayor que la policia. En la década de los ochenta la policia se recupera y alcanza el segundo lugar. Se sabe que la policia, a diferencia del ejército y el Servicio Nacional, carece de vehículos y equipo adecuado para cumplir sus funciones. En 1964 las fuerzas de seguridad tenían 2135 miembros, equivalentes a la proporción de uno por cada 300 habitantes. Esta asfixiante proporción aumentó en 1984 a uno por cada 43 habitantes. Desde la independencia en 1966 hasta 1984, las fuerzas de seguridad han tenido un desmesurado incremento del $673 \%$. $^{38}$

En total, las fuerzas de seguridad tuvieron en 1984 un presupuesto de G\$ (dólares guyaneses) 166.4 millones, superior a los G\$58.3 millones para la salud. los G\$104.4 millones para educación. y los de ambos combinados. ${ }^{39} \mathrm{El}$ sector agricola, que supuestamente es el motor del desarrollo económico, recibió en ese año G\$127 millones. En 1984 los gastos de las fuerzas de seguridad representaban el $10.6 \%$ del presupuesto nacional.

El ejército y el Servicio Nacional están involucrados en proyectos que fomentan el desarrollo de los recursos naturales del país. Esta es una de las funciones expresas de las dos organizaciones, y aun la policia ha recibido órdenes de Burnham de ayudar en esta tarea. ${ }^{+0}$ El ejército se dedica primordialmente a la agricultura, mientras que el Servicio Nacional tiene una mayor gama de actividades económicas. La policía tiene varias fincas, una cooperativa de crédito y otra de ahorro. En el Caribe angloparlante, Guyana es

\footnotetext{
International Team of Observers, Something to Remember: The Report of the Llections in Gilyana. December 1980. Londres. Parliamentary Human Rights Group. Cámara de los Comunes, 1980, p. 25

38 En 1982 un periodista estimaba que las "fuerzas militares y paramilitares" alcanzaban los 20000 hombres. Jeremy Taylor. "Letter from Georgetown: Crisis and Tension in Burnhamland". Express. Trinidad y Tobago, 2 de marzo de 1970.

34 Danns sostiene que es muy posible que los gastos militares sean mucho más altos de lo que revelan las cifras del gobierno. Las asignaciones presupuestarias no incluyen los gastos de armas y municiones que se compran en el exterior. Se dice que el ejército exporta oro para comprar armas. Véase: George K. Danns, "The Role of the Military in the National Security of Guyana", p. 5. Citado de aqui en adelante como: "The Role..." Ensayo a publicarse en el libro editado por Alma Young y Dion Phillips. Militarization in the Non Hispanic Caribbean. (en prensa).

40) Véase para una breve descripción de proyectos realizados a: Juan Aguilar Derpich. Guyana: Otra via al focialisme. Caracas, Editorial El Ojo del Camello. 1973. p. 81-82. Esta obra, un panegirico al régimen de Forbes Burnham, es lo más parecido a un libro de encargo que hayamos visto.
} 


\section{CUADRO 5}

Tamaño estimado de las fuerzas de seguridad

Unidad Militar

\begin{tabular}{lcccc} 
& 1964 & 1966 & 1977 & 1984 \\
& & & & \\
Ejército* & 500 & 750 & 4000 & 4500 \\
Policia & 1635 & 1881 & 3751 & 4208 \\
Servicio Nacional & -- & -- & 4000 & 4500 \\
$\begin{array}{l}\text { Milicia Popular } \\
\text { Guardia Nacional }\end{array}$ & -- & -- & 1000 & 2500 \\
$\quad-$ & - & -- & -- & 2000 \\
$\quad$ Total & 2135 & 2631 & 12751 & 17708 \\
* En 1974 al ejército se le conocía como la Unidad Especial de Servicio. \\
\hline
\end{tabular}

FUENTE: Datos tomados de George K. Danns, "The Role of the Military in the National Security of Guyana", p. 2. cuya fuente de las cifras de la policía son los presupuestos estimados del Gobierno de Guyana de los años 1977 y 1984. Las cifras de las otras organizaciones militares fueron suministradas por oficiales de las mismas organizaciones.

el único país donde las fuerzas de seguridad deben, entre sus objetivos, trabajar en pos del desarrollo económico. Sin embargo, no hay evidencia de que estas actividades económicas sean rentables. Danns concluye: "...su participación en lo económico no es más que un esfuerzo de tenerlos siempre ocupados, aunque sea con pérdidas". 41

El macrodesarrollo de las fuerzas de seguridad se acelera en el contexto de una economia colapsada desde 1977, un desempleo masivo y creciente, una emigración masiva, una escasez de alimentos básicos (que aparece ya en 1976), y una corrupción institucionalizada. Las fuerzas de seguridad no están aisladas de este cuadro tétrico y, aun con el alto desempleo, el reclutamiento ha disminuido, al igual que el profesionalismo, en tanto que la politización ha aumentado. ${ }^{42}$ El desgaste del apoyo político del Congreso Nacional del Pueblo lo ha llevado a depender de las fuerzas militares y paramilitares para mantenerse en el poder.

Una de las estratagemas utilizadas por Burnham para controlar

11 Ihid., p. 37

42 La Alianza del Pueblo Trabajador comentaba en 1983: "Según se percibe en cada nueva crisis, los incentivos de ascenso y aumento de salarios se aplican con cierto afán... Los incentivos son importantes como medios para obtener dinero en efectivo y como signo momentáneo del voluble patronato del dictador. Pero es dudoso que estas medidas sean suficientes para contrarrestar el descontento general que existe dentro de las fuerzas. Los antagonismos de clase están agudizandose: mientras la clase de oficiales comparte las sobras de los gobernantes. y los rasos los sufrimientos de las masas. Crece la evidencia de que más y más hombres y mujeres en las fuerzas de seguridad están escandalizados por los excesos de los elementos fascistas que están bajo la protección del Congreso Nacional del Pueblo". Report of the C'ntral Commitlee of the W'orking People's Alliance. 7 Algust 1983. Georget.own. Working People's Alliance, 1983, p. 4-5. 
las fuerzas de seguridad consiste en la transferencia de la oficialidad de un cuerpo a otro, particularmente desde 1979. De acuerdo con Danns, esta estratagema tiene varias dimensiones. En primer lugar, es un mecanismo nivelador que crea una uniformidad estructural y funcional, especialmente en la jefatura de organizaciones militarmente separadas. Segundo, es un "juego de sillas" diseñado para desbaratar claques fraternales entre los oficiales, no importa cuál sea su orientación ideológica. Los oficiales con actitudes correctas son recompensados y los que tienen actitudes opositoras o indeseables, todo lo contrario. De esta manera también se prueba la lealtad y el compromiso con el partido gobernante. Por último, y tal vez lo más importante, es un mecanismo de control y salvaguarda del régimen en contra de un golpe militar, fundamentado en la institucionalización de la politica de divide y vencerás. 4.3

\section{Otras organizaciones paramilitares}

En 1981 apareció en escena una nueva organización paramilitar, la Guardia Nacional de Guyana, con la tarea de velar por la seguridad de los departamentos gubernamentales, los de oficiales del gobierno y la de los líderes del Congreso Nacional del Pueblo. La dirección está a cargo de oficiales de la policía e incluye oficiales del ejército en calidad de préstamo. La Guardia Nacional no es todavía una entidad legal y su ámbito de acción no ha sido claramente delineado. El aumento en su presupuesto, según el cuadro 5 . de $\$ 5$ a $\$ 13$ millones en 1983, es indicativo de la importancia que la organización está en vías de adquirir. ${ }^{44}$

Para completar el cuadro de las organizaciones paramilitares debemos añadir que algunos ministros y oficiales del Congreso $\mathrm{Na}$ cional del Pueblo tienen sus fuerzas paramilitares personales, reclutadas por ellos mismos y responsables ante ellos solamente. Además, la rama juvenil del partido, el Movimiento Socialista de la Juventud, recibe adiestramiento militar y se ha formado un núcleo militar en la organización.

Por último, un grupo seudorreligioso, la Casa de Israel, cuyo lider es el rabino Washington, un estadunidense negro fugitivo de la ley de su pais, es utilizado por el Congreso Nacional del Pueblo para romper las actividades políticas de la oposición y fortalecer las gubernamentales. También ha servido de rompehuelgas. Washington ha dicho que su grupo recibió adiestramiento militar y que "nosotros no somos solamente un grupo religioso; también se nos considera como algún tipo de organización militar". 45

43 Véase: George K. Danns, Domination and Power in Guyana, p. 165-167. El dictador Rafael L. Trujillo fue un asiduo practicante de este juego, pero esto no impidió que se crearan camarillas en las fuerzas militares, tal como lo pronosticó Jesús de Galíndez en su obra La era de Trujillo, Santiago de Chile, Editorial del Pacífico, 1956, p. 166. El catalizador en este caso pudo haber sido el interés de los Estados Unidos en derrocar a Trujillo. Véase también: Howard Wiarda, Dictatorship and Development. The Methods of Control in Trujillo's Dominican Republic, Gainesville, University of Florida Press, 1968, p. 48.

${ }^{4}$ Danns destaca que la Universidad de Guyana recibió una asignación de menos de $\$ 12$ millones. Véase: George K. Danns. "The Role...", p. 36.

t5 Caribbean Monthly Bulletin. 16, núms. 5-6, mayo/junio, 1982, p. 64. Gran 
Sin duda, el ejemplo más drástico de la politización de las fuerzas de seguridad fue el asesinato, en 1980, de Walter Rodney, historiador prominente y colider de la Alianza del Pueblo Trabajador. Rodney murió a consecuencia de la explosión de una bomba plantada en un radioteléfono portátil por Timothy Smith, un exsargento del ejército. Smith fue adiestrado en Gran Bretaña y ha desaparecido junto con su familia.

La muerte de Rodney fue la culminación de un proceso de represión emprendido por el gobierno contra su partido, al convertirse éste en una alternativa real al Congreso Nacional del Pueblo. La Alianza del Pueblo Trabajador penetró en Georgetown, la capital, y Linden, el pueblo minero, considerados por el Congreso $\mathrm{Na}$ cional del Pueblo como sus baluartes. Los mítines de la Alianza eran muy concurridos, y la incompetencia y corrupción del gobierno los temas obligados de su discurso político. ${ }^{46} \mathrm{El}$ informe de los derechos humanos del Departamento de Estado de los Estados Unidos, correspondiente a 1983, consignó "el hostigamiento y mala conducta policial y el uso de las fuerzas de seguridad para el control político". 4

\section{Ayuda militar de los Estados Unidos y Brasil}

Aunque Burnham necesitó la ayuda de Gran Bretaña y los Estados Unidos para tomar el poder y también la recibió de ambos en sus fuerzas de seguridad en la década de los sesenta, de ahi en adelante se ha mantenido independiente de ambos. Es en la década de los ochenta cuando el ejército recibe ayuda militar de los Estados Unidos y entonces únicamente del Programa Internacional de Educación y Adiestramiento Militar. En 1981 recibieron adiestramiento 11 militares, 22 en 1982 y 10 en 1983 , lo que da un total de 43 en tres años. ${ }^{48}$ El costo para los Estados Unidos fue de $\$ 14000$ en 1982 y $\$ 25000$ en $19833^{49}$ En 1984,50 militares guyaneses estaban prestos a trasladarse a los Estados Unidos bajo este

parte de la información de las fuerzas militares y paramilitares que hemos utilizado proviene de: Moses Bhagwan. "Background Information on the Militarisation Process in Guyana (Notes)". mimeografiado. Distribuido en el Seminario sobre las Amenazas a la Paz en el Caribe y América Central. Aguas Buenas. Puerto Rico, 2-7 de octubre de 1984.

theorge K. Danns. Domination and Poner in Gllana, p. 181-183. El hostigamiento a la Alianza continuó aún después del asesinato de Rodney. Una semana antes del aniversario de la muerte de Rodi $2 y$, el ejército y algunas organizaciones paramilitares llevaron a cabo por 10 dias un ejercicio militar. la Operación Rayo. dizque contra el tráfico de narcóticos de una organización llamada W.O.P., cuyo lider se llamaba Eusi (una obvia referencia a Eusi Kwayana. colider de la Alianza), de otra llamada P.O.P.. que controlaba una pareja indoriental (referencia a los Jagan). y una última organización que dirigia un arzobispo (referencia a las Iglesias. con las que el régimen ha chocado fuertemente). todos en colaboración con venezolanos. Véase: Caribbean Contact, junio de 1981.

Catholic Standard, Guyana, 19 de febrero de 1984, p. 1. En anos recientes han proliferado las acusaciones de que la policia está ejecutando a criminales. Véase: "Guyana Human Rights Report. 1983", Human Rights Internet Reporter, 9, núm. 4. marzo/junio, 1984, p. 622-623.

${ }^{+*}$ U.S. Department of Defense, Foreign Military Sales, Foreign Military Construction Sales and Military Assistance Facts, September 30. 1983. Washington, D. C.. Data Management Division, Comptroller, DSAA, 1983, p. 92-93.

+1" Vease: /hid., p. V. 78-79. 
programa. Ese año Guyana iba a recibir $\$ 98000$ en ayuda de seguridad: $\$ 48000$ bajo LP 480 y $\$ 50000$ en servicios de adiestramiento bajo el Programa Internacional de Educación y Adiestramiento Militar. ${ }^{50}$ Esta asignación del Programa Internacional de Educación y Adiestramiento Militar se repite para los años de 1985 y 1986.5

En 1982 Burnham visitó Brasil y acordó la reanudación de los lazos militares. Asimismo, Brasil le concedió un crédito de $\$ 17$ millones para equipo militar. ${ }^{52}$ Desde hace algún tiempo se rumora que los principales proveedores de armas de Guyana son Cuba y, más recientemente, Corea del Norte. Sin embargo, la realidad es un aumento en las compras comerciales de armas a los Estados Unidos. De un total de \$1 421000 que Guyana gastó de 1950 a 1983 en compras a los Estados Unidos, \$1 227000 , equivalente al $86 \%$, lo gastó de 1981 a 1983 . $^{\text {s }}$

El crecimiento de las fuerzas de seguridad y paramilitares en Guyana ha sido impulsado fundamentalmente para enfrentar un enemigo interno. Aunque Venezuela ha sido agresiva en varias ocasiones, el gobierno ha usado este pretexto para fomentar el macrodesarrollo de las fuerzas de seguridad, que han sido el instrumento para que el Congreso Nacional del Pueblo pueda mantenerse en el poder en una sociedad en crisis. ${ }^{54}$ No obstante, no se puede descartar la posibilidad futura ae que Venezuela (u otro país vecino) sea utilizado por los Estados Unidos para presionar a Guyana, aun invadirla, usando como pretexto su reclamo territorial, motivado otra vez tras la expiración de los 12 años del Protocolo de Puerto España.

Aquí debemos destacar que en momentos claves, Burnham,

5" Latin America Regional Reports: Caribbean Report. 28 de septiembre de 1984. rc-84-08. p. 7.

51 Véase: "International Security and Development Cooperation Program, April 1984". Special Report num. 116. U.S. Department of State, p. 14, y "Foreign Assistance Program: FY 1986 and 1985 Supplemental Request, May 1985", op. cit. p. 14.

S- Caribbean Monthly Bulletin, 16, núm. 10, octubre, 1982, p. 8.

$\$$ Véase: U. S. Department of Defense, op. cit., p. 42-43.

st En 1979 Burnham contestaba la demanda de los sindicatos de un salario mínimo de G\$14 de esta forma: "Ustedes quieren G\$14 o quieren el Esequibo?" Véase: Latin America Regional Reports: Caribbean Report. 23 de julio de 1983 , rc-83-06. p. 7-8. Jagan escribe: "Otra vez a los guyaneses se les da de comer la misma conocida aseveración: 'Guyana está siendo atacada'. Esta es una diversión muy útil para el CNP." Cheddi Jagan. "Straight Talk: What Kind of Attack?", Itiror, I de agosto de 1984. En 1982 el gobierno comenzó una venta de bonos de defensa para levantar $\$ 10$ millones para la compra de equipo militar. Véase: Caribhean Monthly Bulletin. 16. núm. 4, abril. 1982, p. 29-30.

si En 1982 Eusi Kwayana escribia: "Es muy probable que en las circunstancias presentes. EE.UU. haya ordenado a ambos lados mantener la paz, mientras utiliza la cuestión para sacar ventaja política. La venta de los aviones F-16 a Venezuela lleva consigo sin duda la condición de que no se usen contra Guyana, que a su vez ha dado los primeros pasos en un nuevo programa militar (Programa Internacional de Educación y Adiestramiento Militar). Todos los indicadores apuntan a que EE.UU. está trabajando duro para que ambos lados lleguen a un trato sobre un acuerdo, y puede que ahora mismo estén llevando a cabo negociaciones secretas y separadas entre ellos. El máximo interés de EE.UU., el aislamiento de Cuba, es la clave para su propuesta en el conflicto fronterizo entre Guyana y Venezuela. No desea ninguna perturbación activa en el Pacto del Amazonas, o entre sus aliados vecinos." Eusi Kwayana. "The US Card in Venezuela-Guyana Land Row", Caribhe'all Contact, mayo de 1982. p. 1. 
muy hábilmente, logró la colaboración y el apoyo, aunque condicionado, del Partido Progresista del Pueblo, como en la nacionalización de DEMBA en 1971 y las otras nacionalizaciones de 1975 a 1977. En ambas ocasiones Burnham dio al traste con lo acordado, llevando de paso al país a una debacle económica. A lo largo de los años, Burnham ha tomado ventaja de que la única alternativa al Congreso Nacional del Pueblo en el poder han sido el Partido Progresista del Pueblo y la Alianza del Pueblo Trabajador. ${ }^{56}$ Ante este dilema los Estados Unidos han optado históricamente por apoyar, unas veces con más ahínco que otras, a Burnham, particularmente desde 1977, cuando Guyana recurrió al Fondo Monetario Internacional. ${ }^{57}$

Sin embargo, este apoyo de los Estados Unidos a Burnham, a veces renuente, a veces con gusto, en los dos últimos años había desaparecido. Abiertamente los Estados Unidos evitaron que Guyana recibiera préstamos del Banco Interamericano de Desarrollo. Burnham expulsó a dos funcionarios de la embajada de los Estados Unidos en Guyana. Caso insólito, rechazó un embajador estadunidense. Esta situación de tensión se dio en un momento en que Guyana se acercaba a las multinacionales de la bauxita para que se hicieran cargo de esta industria. Cabe preguntarse qué elementos nuevos han surgido que parecen haber trastocado la situación.

\section{Rumores de golpe militar y otro falso intento de diálogo}

Antes de la muerte de Burnham el 6 de agosto de 1985, los rumores de un golpe militar se estaban haciendo habituales. Tan es así, que la prestigiosa publicación Latin America Regional Reports: Caribbean Report del 29 de marzo de este año tituló ese número "El dilema de Burnham: cómo detener el golpe sin provocarlo". La publicación mencionó, como un elemento novel en el panorama político guyanés, a una organización de derecha, el Partido Conservador de Guyana, radicado en Canadá y los Estados Unidos, el cual solicitó a la administración Reagan "un plan factible" para prevenir que Guyana se convirtiera en "una base de avanzada sovieticocubana en el hemisferio". Esta organización se presentó como "socios civiles potenciales de un régimen militar", que impediría la alianza de los "socialistas cooperativistas" de Burnham con los comunistas de Jagan.

\footnotetext{
"Danns afirma que "el no ser socialista en Guyana es ser un desviado, ya que el gobierno y el partido de oposición principal. el PPP. y los grupos radicales de protesta... todos proclaman sus tendencias izquierdistas. Si el CNP de Burnham está a la izquierda del centro. todos los otros grupos y partidos politicos están a la izquierda de la izquierda." George K. Danns. op. cil., p. 176.

\$7 Véase: Clive Y. Thomas, "El Fondo Monetario Internacional y Guayana", El Caribe' Conlemperinco), núm. 8. junio de 1984, p. 57-65.

s. Latin America Regional Reports: Caribbean Report, 29 de marzo de 1985 , rc-85-03, p. 1. Miembros de este partido fueron arrestados en 1983 en Canadá por tratar de enviar armas a Guyana con el propósito de derrocar a Burnham. En abril de 1985 un juez canadiense decidió que siete guyaneses serian juzgados por el delito de conspirar para derrocar el gobierno de Guyana. Véase: Caribbean MonIhl! Bulletin, 17. núms. 11-12. noviembre/diciembre. 1983, p. 70-71, y Latin .tmerica Regional Reports: Caribbean Report. 10 de mayo de 1985, rc-85-04. p. 8. En junio de 1980 varias personas que supuestamente se estaban adiestrando en el uso
} 
Esto último responde al llamado de Burnham al Partido Progresista del Pueblo para que ambos sostuvieran un diálogo constructivo (¿el tercero?) que culminase en un gobierno nacional. ${ }^{59}$ La realidad parece ser que ambos. el Partido Progresista del Pueblo y la Alianza del Pueblo Trabajador, habian sido debilitados terriblemente por el continuo acosamiento. la represión y la persecución de Burnham, mientras que el Congreso Nacional del Pueblo se ha mantenido en el poder. gracias a su manipulación de las fuerzas de seguridad y cierto apoyo internacional por su retórica progresista en los foros internacionales y tercermundistas. En junio de $1985 \mathrm{el}$ parlamento aprobó la ley, con la oposición de todos los partidos, excepto. por supuesto. del Congreso Nacional del Pueblo, que permite a las fuerzas de seguridad detener a personas por tiempo indefinido sin llevarlas a juicio si piensan que es "probable que causaran la subversión de las instituciones democráticas". 60

Aunque todas las fuerzas de seguridad se vigilan y espian entre si, se juzga que la ejecución de un golpe logrado sólo puede llevarlo a cabo el ejército. quien junto con la policia. son considerados como "las fuerzas sobre las cuales el CNP tiene menos control ideológico". "Aquí vemos que surge como elemento nuevo y de significancia el Programa Internacional de Educación y Adiestramiento Militar de los Estados Unidos, cuyo impacto está dirigido al aspecto ideológico del ejército.

De vital importancia ha sido el involucramiento del ejército $y$ las fuerzas de seguridad en la corrupción y economia paralela que ha brotado por la crisis económica, no obstante el aumento en salarios y subsidios al ejército por el gobierno para evitar la insatisfacción en este cuerpo. Otro motivo de preocupación e insatisfacción en un sector del ejército es la política de no alineamiento del país. la cual se entiende viene a significar que en realidad Guyana no puede contar con ayuda en caso de una invasión de Venezuela. de otro de sus vecinos, o de los Estados Unidos. ${ }^{62}$ En 1984 el Financial Times informaba de cierto malestar en el ejército por la situación económica y que la administración Reagan trataba de desestabilizar a Burnham para reemplazarlo por el ministro de Agricultura, Hamilton Green. ${ }^{63}$ Por otro lado, Burnham perdió el apoyo del Congreso de Sindicatos en septiembre de 1984, y estaba en plena campaña de hostigamiento contra el nuevo presidente del

de armas de fuego, fueron arrestadas por la policia y acusadas por intentar derrocar al gobierno. Mas tarde fueron dejadas en libertad al encontrarse que la evidencia era inadmisible por obtencrse por la fuerza. Véase: Caribbean Momthly Bulletin. 14. nums. 6-7. junio/julio. 1980. p. 25. Y Latin America Regional Reports: Caribhe'ell Repor\%. 10 de diciembre de 1982. re-82-10. p. 3.

"Una de las demandas del Partido Progresista del Pueblo, a discutirse con urgencia. era el velar por la soberanía nacional. la independencia y la integridad territorial. por lo que era necesario que se expandieran "las milicias populares en cuda pueblo, aldea y comunidad". "Guyana's Political Opponents Inch Towards Unity Talks". C "ariblecan Insighth. julio. 1985. p. 5.

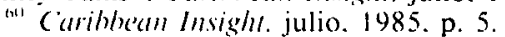

"C Carihbean Invight julio, 1985. p. 5-6.

"- Danns afirma que "el no-alineamiento de Guyana la coloca en la posición no envidiable de carecer de amigos confiables y de tener enemigos seguros. .... En términos reales. el no-alineamiento para Guyana significa soledad y falta de amistad". Véase: George K. Danns. "The Role...", p. 21-22.

6.3 Hugh O'Shaughnessy. "Reports of Unrest in the Guyana Defence Force", Financial Times, 15 de mayo de 1984. 
mismo, George Daniels. El Congreso es el representante de los trabajadores del sector público. ${ }^{64}$

\section{La muerte de Burnham}

En 1983 el periódico Catholic Standard afirmaba que sólo quedaban fuera de Burnham, luego de los vaivenes y cambios de los últimos 20 años, cinco sobrevivientes a nivel ministerial: Hamilton Green. Ptolemy Reid. Desmond Hoyte. Cammie Ramsaroop y Steve Naraine. Añadía el periódico:

Por primera vez hay un desbalance notable entre los vicepresidentes. en términos de su poder e influencia. La acumulación de todos los ministerios productivos en manos de Green puede ser una señal al FMI que Burnham está dispuesto a tratar con mano dura las uniones y a cualquiera que se le ocurra crear malestar laboral, por las medidas de austeridad que son inminentes.

Ya veremos qué pasa si Green fracasa en manejar efectivamente las uniones. en estimular la economia o en resolver el estancamiento en los sectores de la bauxita y manufactura.

Al hacer esta clase de evaluaciones en Guyana, uno debe recordar constantemente que los cálculos políticos normales tienen que tomar en consideración el hecho de que el apoyo popular, o la fuerza entre los miembros del partido es de poca importancia.

Para algunos propósitos. las organizaciones militares -y su influencia 'n el gabinete es uno- constitu!en la membresia del partido y' sustituyen al apolo popular.

El trabajo de Hoyte es proveer el apoyo burocrático para el empuje de producción que encabeza Green en términos de planificación, la atracción de inversiones, el desarrollo de oportunidades de comercio y la búsqueda de divisas. ${ }^{65}$

A mediados de 1984 la economía no demostró mejoria y al retirarse Ptolemy Reid de primer ministro por motivos de salud, Desmond Hoyte fue nombrado su sustituto. Claramente la gestión de Green no tuvo éxito pero se le nombró primer ministro adjunto, un puesto de nueva creación al que también se designó a Haslyn Parris y Mohammed Shahabuddeen, dos tecnócratas que al igual que Hoyte estaban más cerca de Burnham que del partido.

La transferencia de poder a la muerte de Burnham fue de acuerdo con la constitución, y por eso Hoyte fue nombrado presidente. Sin embargo, se rumoraba fuertemente que Green pronto

int Latin tmerica Regional Reports: Caribbean Report. 29 de marzo de 1985. rc-85-03. p. 5.

"Analyst. "Green Star in Ascendancy", Catholic Standard, 15 de mayo de 1983. p. 1. 4. (Subrayado nuestro.)

th Green fue nombrado secretario general del Congreso Nacional del Pueblo a la edad de 28 años. Green. que ahora tiene 53 aǹos, ha estado a cargo de casi todos los ministerios. Parris estuvo a cargo de GUYMINE y fue quien anunció en julio de 1981 la contratación de la Green Construction Co. para la explotación a cielo abierto de la bauxita. Shahabuddeen, de 55 años, fue nombrado a fines de la década de los setenta ministro de Justicia y procurador general. Véase: Caribbean 1/omhly Bullerim. 15. núm. 7. julio. 1981. p. 34: Latin America Regional Reports: Caribhean Répeml. 24 de agosto de 1984, rc-84-07, p. 8; y Latin America Regional Roports: Caribhean Report, 27 de septiembre de 1985, rc-85-08, p. 4. 
aspiraría al puesto porque contaba con el apoyo de la mayoría del partido y del ejército. ${ }^{6}$

Es importante destacar que una de las primeras medidas de Hoyte fue ascender al brigadier general Norman McLean, que ocupaba el puesto de comandante en jefe del ejército. a mayor general. y al coronel David Granger, comandante del ejército, a brigadier general. ${ }^{\text {t8 }}$ Obvia movida para ganar el favor del liderato militar del ejército. A principios de 1986 se estimaba que la posición de Green se habia debilitado con el nombramiento de Ranji Chandisingh (quien fuera lugarteniente de Jagan en el pasado) como segundo en el partido y de Shahabuddeen como primer ministro adjunto y vicepresidente. ${ }^{69}$

Hoyte estuvo muy cerca de Burnham y ha sido miembro del Parlamento desde 1968. En 1969 fue nombrado ministro de Asuntos Internos. en 1970 de Finanzas. en 1974 de Desarrollo Económico, en 1981 vicepresidente y en 1984 primer vicepresidente. Los efectos de la crisis económica los sufrió en carne propia, en abril de 1985, al fallecer dos hijas suyas adolescentes y quedar su esposa gravemente herida en un accidente automovilistico por las pésimas condiciones de las vias públicas. Hoyte ha atacado consistentemente al Catholic Standard y tiene tres de las cinco demandas de libelo contra el periódico. ${ }^{70}$

\section{Hojte continúa el acercamiento a los Estados Unidos}

Aunque Hoyte estuvo presente en las conversaciones con el ministro de Relaciones Exteriores de Cuba, Isidoro Malmierca, en diciembre de 1984, se ha especulado que la política exterior de Guyana en el futuro será menos dinámica, replegándose al nivel regional, y más plegable a las posiciones de Estados Unidos, en vista de la precariedad de la economía y las relaciones futuras con el Fondo Monetario Internacional y el Banco Mundial.

$Y$ asî parece haber acontecido. Las conversaciones entre el partido gobernante y el Partido Progresista del Pueblo se fueron a pique con la celebración de elecciones amañadas el 9 de diciembre de 1985, en las que el Congreso Nacional del Pueblo obtuvo 42 de los 53 asientos parlamentarios. ${ }^{71}$ El editor de Caribbean Contact las describió de esta manera:

\footnotetext{
Vease: Latin fmerica Regimal Reports: Carihbean Report, 23 de agosto de 1985. re-85-07. p. 2-3.

Vease: "Hoyte Faces Pressure for Political Changes in Guayana". Carihbean Insig/t. septiembre. 1985, p. 2.

"ii Latin . Imerica Regional Reperts: Caribhean Report. 21 de febrero de 1986. re-86-02. p. 8

" Burnham y Green fueron los otros dos que demandaron. En una carta a Andrew Morrison, S. J., editor del periódico, Hoyte le decía: "Es de lamentar, que con sus pretensiones de ser uno de los vice regentes de Dios en la tierra. usted persista en exponerse como hombre de poca fibra moral. una obscenidad en sotana". Latin

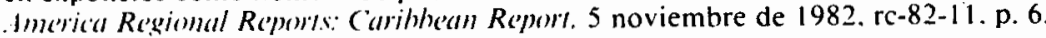

${ }^{\prime \prime}$ Esta vez el gobierno rechazó la presencia de observadores, al igual que las peticiones de la oposición de que el ejército fuera acuartelado ese día. El mayor general McLean manifestó que "sería arriesgado acuartelar a los soldados en sus barracas en un periodo de alta tensión. No podemos permitir que vengan personas a intervenir con el curso normal de las elecciones". Los restantes miembros electos al Parlamento se distribuyeron de esta forma: el Partido Progresista del Pueblo - 8.
} 
El familiar y sórdido catálogo de privaciones a ciudadanos del derecho a votar, de votaciones múltiples, de la expulsión de los custodios de las urnas, de amenazas e intimidación, de la violencia, y la colusión entre la policía y el personal del ejército caracterizaron los comicios. ${ }^{72}$

Las elecciones fueron severamente criticadas por la prensa regional, las iglesias e inclusive algunos jefes de gobierno, como el primer ministro James Mitchell de San Vicente y John Compton de Santa Lucia. ${ }^{73}$ Estos últimos pronto se tragaron sus palabras. En enero de 1986 se reunieron en la diminuta isla de Musquite los primeros ministros de Barbados, Dominica, Granada, San Cristóbal, Santa Lucia y San Vicente para discutir con Hoyte los resultados electorales. La secuela de la reunión fue que los primeros ministros declararon que estaban complacidos con las explicaciones de Hoyte y por ende dispuestos a trabajar con él. Mientras tanto el Catholic Standard indicaba que "la señal ha llegado de que el bote del presidente Hoyte no puede bajo ninguna circunstancia ser hundido en vista de los intereses estratégicos de EEUU'. ${ }^{74}$

Durante la presentación del presupuesto de 1986 al Parlamento en febrero, el ministro de Finanzas hizo claro que "se están haciendo todos los esfuerzos para retornar a ser elegibles al Fondo [Monetario Internacional]". ${ }^{75}$ También reveló que se está preparando legislación para permitir el establecimiento de bancos extranjeros, de forma que éstos se involucren en la economia local. En un intento de aparentar, en cierta medida, que continuaba el juego de Guyana con las dos potencias mundiales, en octubre de 1985. Hoyte aceptó, como regalo de la URSS en el veinte aniversario del ejército de Guyana, tres helicópteros de combate. ${ }^{76}$

Dentro de este cuadro de las fuerzas de seguridad, el ejército parece ser la única organización que por la misma política de Burnham no se ha deteriorado como las otras, por lo que su peso puede ser crucial para el nuevo gobierno. A la muerte de Burnham se percibia descontento en ellas por la política, tanto interna como externa, del Congreso Nacional del Pueblo. El único elemento nuevo de importancia con respecto al ejército es su vínculo con el complejo militar estadunidense por medio del Programa Internacional de Educación y Adiestramiento Militar. En suma, la situación es una de incertidumbre, en compás de espera, pendiente de las aspiraciones de Green y de la crítica situación económica por la que atraviesa el país, la que es probable empeore de ajustar el gobierno su política económica a las directrices del Fondo Monetario Internacional.

la Alianza del Pueblo Trabajador - 1, y la Fuerza Unida - 2. Véase: Eusi Kwayana, "Robbed at Gunpoint", Caribbean Contact, marzo de 1986, p. 7, y Latin America Regional Reports: Caribbean Report, I noviembre de 1985, rc-85-09, p. 3.

72 C. M. Hope, “An Absurdity?", Caribbean Contact, enero de 1986, p. 1.

13 Véase: Correspondent, "Guyana's Poll", Caribbean Contact, febrero de 1986, p. 9.

${ }^{74}$ Latin America Regional Reports: Caribbean Report, 21 de febrero de 1986, rc-86-02, p. 1 .

${ }^{75}$ Latin America Regional Reports: Caribbean Report. 17 de enero de 1986, rc86-01, p. 7. Véase también: Latin America Regional Reports: Caribbean Report. 28 de marzo de 1986, rc-86-03, p. 2.

to Véase: Caribbean Insight, noviembre, 1985, p. 8. 